Universitas, Volumen 1, Número 2, 2008, 27-30

๑) 2008 UNAN-León, Editorial Universitaria

\title{
Elaboración y Caracterización de microcápsulas gastrorresistentes de Diclofenac obtenidas por Gelificación lónica
}

\author{
José Calero*, Yader Francisco Sánchez, Roberto Tórrez, Ena Hernann, Kaitlin López. \\ Departamento de Tecnología Farmacéutica y Departamento de Analisis, Facultad de Ciencias Quimicas. \\ Universidad Nacional Autónoma de Nicaragua, León (UNAN-León).

\section{RESUMEN}

Se obtuvieron microcápsulas de diclofenac por gelificación iónica de una solución de alginato. Se determinaron parámetros tales como morfología, distribución de tamaño de partícula, capacidad de encapsulación y estudios de liberación in vitro entre otros. La técnica desarrollada permitió obtener un sistema con características micrométricas y una buena eficacia de encapsulación

Palabras claves: Alginato; Gelificación ionica; Microcapsulas; Diclofenac.

\section{INTRODUCCIÓN}

La microencapsulación, según la literatura, nos ayuda en la obtención de sistemas de liberación controlada o sostenida de fármacos. Nos permite también, la posibilidad de enmascarar sabores y olores desagradables de principios activos y proteger al producto contra la oxidación, fotosensibilidad, volatilidad y en algunos casos muy importantes como es la reducción de la acción irritante gastrointestinal de algunos activos ${ }^{[1]}$.

En el inicio, para la microencapsulación se usaron solventes orgánicos, lo que no la hacía factible para aplicaciones biológicas. En los años 80 , se comenzaron a usar sustancias naturales como proteínas (colágeno, gelatina) y polisacáridos (agar, alginato cálcico, carragenan), los cuales mostraron buena biocompatibilidad y han demostrado una rápida incorporación de los principios activos en los sistemas.

Los alginatos son uno de los polímeros más utilizados en la microencapsulación. Ellos son extraídos primariamente de tres especies de algas marrones. Los alginatos son una familia de polisacáridos lineales no ramificados, conteniendo cantidades variables de ácido $\left(1,4^{\prime}\right) \beta$-D-mannurónico y de ácido $\alpha$-L-glucorónico.

La composición y extensión de las secuencias y el peso molecular determinan las propiedades físicas de los alginatos ${ }^{[2]}$. Las microcápsulas de alginato cálcico, son generalmente preparadas por dos métodos ${ }^{[3]}$ :

a-por goteo de una solución de alginato de sodio en una solución de una sal de calcio.

b-por gelificación del alginato en una emulsión A/O.
Las microcápsulas producidas por el primer método son generalmente grandes y el empleo de una técnica de goteo por jeringa, no es aplicable para una escala industrial. La producción de microcápsulas por emulsificación puede ser obtenida por gelificación externa o interna.

La gelificación externa, donde una sal de calcio soluble es agregada en el seno de una emulsión $A / O$, es la más estudiada. Sin embargo, el tamaño de partícula no puede ser bien controlado y las partículas tienden a coagular en grandes masas antes de adquirir la consistencia apropiada ${ }^{[4]}$.

El objetivo de este trabajo ha sido microencapsular diclofenac en una matriz de alginato por una metodología simple, y estudiar la disolución de las microcápsulas.

\section{MATERIALES Y MÉTODOS}

Alginanto de sodio, cloruro de calcio, agua destilada, diclofenac sódico; hidróxido de sodio; ácido clorhidrico; trisodio fosfato dodecahidratado. Todos los materiales fueron utilizados sin ningún tratamiento previo.

\subsection{Preparación de las micrcapsulas de alginato}

Se prepararon $200 \mathrm{~mL}$ de una solución de alginato de sodio de la siguiente manera: $3,0 \mathrm{~g}$ de alginato se dispersaron en $100 \mathrm{~mL}$ de agua destilada y se aforaron a $200 \mathrm{~mL}$.

Luego, $3.0 \mathrm{~g}$ de cloruro de calcio se dispersaron uniformemente en $200 \mathrm{~mL}$ de agua destilada. A la solución de alginato de sodio se le adicionaron $4.0 \mathrm{~g}$ de diclofenac sódico bajo constante agitación. 
Una vez dispersado el fármaco se inició el goteo sobre la solución de cloruro de calcio obteniéndose las microcápsulas. Las microcápsulas así obtenidas, se secaron en horno de bandeja a una temperatura de $40^{\circ} \mathrm{C}$ hasta obtención de peso constante.

\subsection{Análisis del tamaño de partícula de las Microcápsulas y morfología}

Una vez secas, se determino el tamaño de las microcápsulas usando la técnica del tamizado, para lo cual se utilizaron los tamices de los siguientes tamaños: 2.5, 1.6, 1.0 y $0.63 \mathrm{~mm}$ (Tabla 1) (Figura 4).

Tabla 1: Granulometría de las microcápsulas obtenidas.

\begin{tabular}{|c|c|}
\hline Abertura de tamiz & Porcentaje retenido \\
\hline $2.5 \mathrm{~mm}$ & 0.00 \\
\hline $1.6 \mathrm{~mm}$ & 70.07 \\
\hline $1.0 \mathrm{~mm}$ & 23.47 \\
\hline $0.63 \mathrm{~mm}$ & 0.23 \\
\hline Menor 0.63 & 6.23 \\
\hline
\end{tabular}

Micropartículas desecadas fueron monitoreadas mediante microscopía óptica (Arcano XSZ- 107 E, 10X (Figura 1).

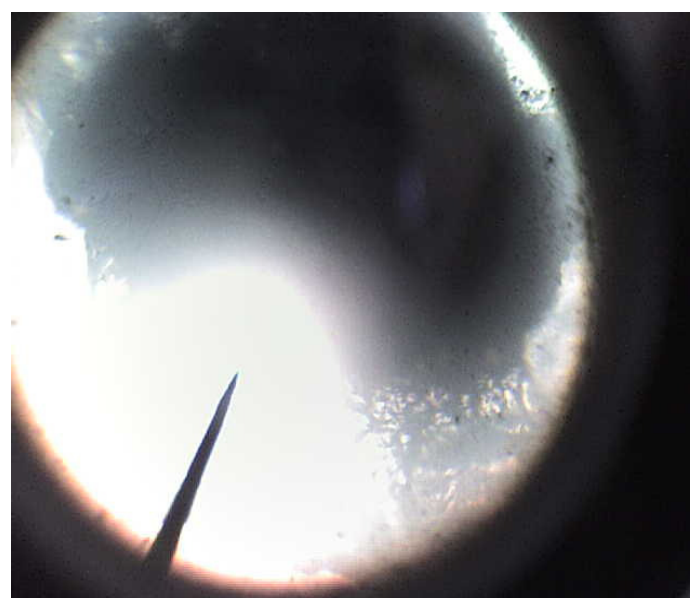

Figura 1. Microcápsula de Diclofenac por microscopía óptica

\subsection{Determinación del contenido de principio activo}

Aproximadamente $68.0 \mathrm{mg}$ de microcápsulas, fueron exactamente pesadas y diluidas a $100.0 \mathrm{~mL}$ utilizando $10.0 \mathrm{~mL}$ de hidróxido de sodio y aforando con agua destilada. La muestra fue sometida a un baño de agua ultrasónico hasta producir la ruptura de las partículas. Se filtraron, a través de un filtro de 0,45 $\mu \mathrm{m}$, y luego de diluciones apropiadas la muestra se leyó espectrofotométricamente a $276 \mathrm{~nm}$ (Espectrofotómetro UV-Vis Hewlett Packard 8453).

\subsection{Rendimiento de la producción (\%Ren)}

Nos refleja el porcentaje de Microcápsulas obtenidas y se obtiene por la siguiente ecuación:

$$
\% \text { Ren }=\frac{\text { Cantidad de microcápsulas obtenidas }}{\text { Cantidad de microcápsulas esperadas }} \times 100
$$

\subsection{Eficacia de la encapsulación}

Este se calcula a partir de la siguiente ecuación:

$\%$ Encapsulado $=\frac{\text { Cantidad de principio activo encapsulado }}{\text { Cantidad teórica de principio activo }} \times 100$

\subsection{Contenido de principio activo ( $\mathrm{Cp} a)$}

Hace referencia a la cantidad de medicamento encapsulado en la microcápsula, y se calcula de la siguiente manera.

$$
C p a=\frac{\text { Cantidad de principio activo encapsulado }}{\text { Peso final de la microcápsula }} \times 100
$$

\subsection{Estudios de liberación in vitro}

Ensayos de liberación in vitro fueron efectuados utilizando un equipo disolutor Hanson Research SR8 plus de seis vasos de vidrio bajo las siguientes condiciones:

\section{Etapa Buffer}

\section{Procedimiento:}

Los estudios de disolución se realizaron a $37 \pm 0.5^{\circ} \mathrm{C}$ en 900 $\mathrm{ml}$ de solución amortiguadora de fosfato de $\mathrm{pH} 6.80 \pm 0,05$. Las microcápsulas encapsuladas fueron colocadas en el aparato 2 (paletas), rotadas a una velocidad de $50 \mathrm{rpm}$. Las muestras fueron retiradas al tiempo especificado en la USP 30-NF 256 y determinando el contenido disuelto de $\mathrm{C}_{14} \mathrm{H}_{10} \mathrm{Cl}_{2} \mathrm{NNaO}_{2}$ a partir de las absorbancias UV a la longitud de onda de máxima absorción, aproximadamente $276 \mathrm{~nm}$. Se realizaron tres determinaciones al lote de las microcápsulas.

Tolerancia-A los 45 minutos se disuelve no menos del $75 \%(Q)$ de la cantidad de $\mathrm{C}_{14} \mathrm{H}_{10} \mathrm{Cl}_{2} \mathrm{NNaO}_{2}$ declarada en la etiqueta.

\section{RESULTADOS Y DISCUSIÓN}

\subsection{Preparación de microcápsulas de alginato}

Durante la preparación de Microcápsulas, se observó que el número de lavadas tiene influencia en la liberación del principio activo, notándose que en algunos lotes se liberaba mayor porcentaje de principio activo que 
en otros, esto probablemente por debilitamiento de la cubierta protectora de la microcápsula. Actualmente, se esta haciendo otro estudio para corroborar esta información.

\subsection{Granulometría de las Microcápsulas.}

Según la literatura, la gelificación iónica nos permite obtener tamaños de microcápsulas que van desde 1 $\mathrm{mm}$ hasta los $5 \mathrm{~mm}$. En nuestro caso, el $77.7 \% \pm 2.55$ de las Microcápsulas tienen un tamaño promedio de 1.6 $\mathrm{mm}$ y un $19.9 \% \pm 3.68$ tienen un promedio de $1 \mathrm{~mm}$. Las microcápsulas exhibieron unas formas redondeadas recién preparadas (figura 2) y una forma redondeada irregular una vez secas. (figura 3 )

\subsection{Rendimiento de la producción.}

El rendimiento de la producción obtenido fue de $76.14 \%$ \pm 1.54 , lo que según nuestras especificaciones cumple lo establecido.

\subsection{Eficacia de la encapsulación.}

La eficacia del método de encapsulación dio 89.56\% \pm 0.18 . Cumpliendo las especificaciones previamente establecidas por el formulador.

\subsection{Contenido de principio activo.}

El contenido de principio activo encontrado fue de 81.04 $\% \pm 0.93$.

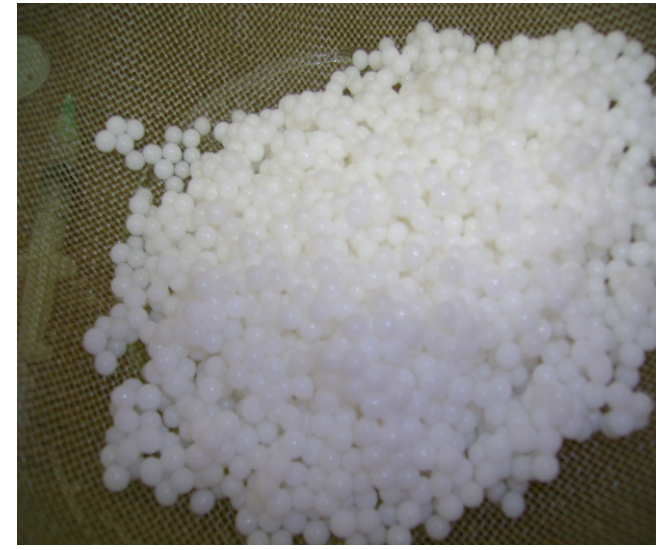

Figura 2. Microcápsulas de diclofenac recién preparadas.

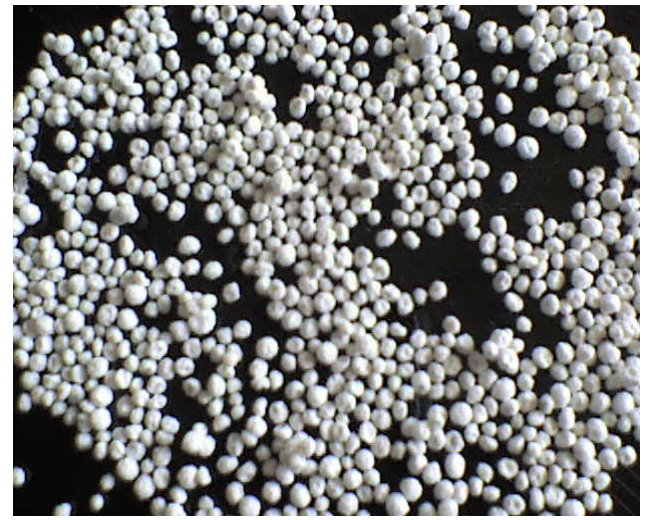

Figura 3. Microcápsulas de diclofenac secas.

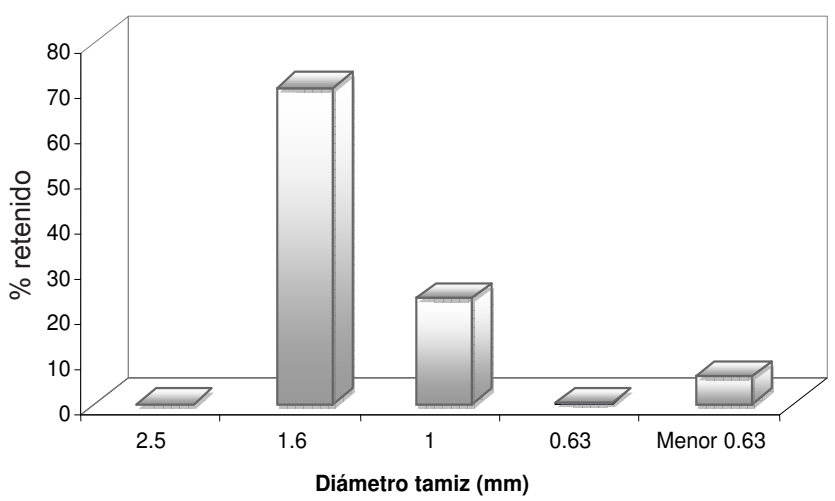

Figura 4. Granulometría de las Microcápsulas

\subsection{Disolución}

Los resultados del ensayo de disolución fueron del $91.59 \% \pm 3.94$ (tabla 2). Lo que satisface la especificación de la USP 30-NF 25.

Tabla 2. Resultados con sus respectivas especificaciones.

\begin{tabular}{|c|c|c|c|}
\hline Especificación & Rango & Resultado & Conclusión \\
\hline Morfología & $\begin{array}{c}\text { Forma esférica } \\
\text { irregular }\end{array}$ & $\begin{array}{c}\text { Microcápsula } \\
\text { esféricas } \\
\text { irregulares }\end{array}$ & cumple \\
\hline $\begin{array}{l}\text { Tamaño de } \\
\text { partícula }\end{array}$ & $\begin{array}{l}\text { Mayor del } 70 \% \\
\text { entre } 1-2 \mathrm{~mm}\end{array}$ & $97.6 \%$ & cumple \\
\hline $\begin{array}{l}\text { Rendimiento de } \\
\text { producción }\end{array}$ & Mayor del 70\% & $76.14 \% \pm 1.54$ & cumple \\
\hline $\begin{array}{c}\text { Eficacia de } \\
\text { encapsulación }\end{array}$ & Mayor del 80\% & $89.56 \% \pm 0.18$ & cumple \\
\hline $\begin{array}{l}\text { Contenido de } \\
\text { principio activo }\end{array}$ & Mayor del 75\% & $81.04 \% \pm 0.93$ & cumple \\
\hline Disolución & $\begin{array}{c}Q \text { mayor de } 75 \% \\
\text { en } 45 \text { minutos } \\
\text { etapa buffer }\end{array}$ & $91.59 \% \pm 3.94$ & cumple \\
\hline
\end{tabular}




\section{CONCLUSIONES}

Las microcápsulas de diclofenac fueron obtenidas por gelificación iónica, mediante una metodología simple y reproducible. Se observó, que el número de lavadas ejerce una influencia en la formación de la cubierta lo que puede incidir posteriormente en la disolución.

Las microcápsulas obtenidas no son aptas para una liberación controlada, pero sí adecuadas para una formulación gastrorresistente que protege la mucosa gástrica, manteniendo sus propiedades terapéuticas y además, podrían ser utilizadas para enmascarar el sabor desagradable del diclofenac, así como, para evitar incompatibilidades de este con otros componentes de la formulación u otros principios activos.

\section{BIBLIOGRAFIA}

1. Lamas MC, Bregni C, Frías M, Velázquez R. (1998). Hydrogel microspheres for flutamide obtained by múltiple emulsions. S.T.P. Pharma Science; 8(6): 375-378.

2. Gombotz WR, Wee SF. (1998). Protein release from alginate matrices. Advanced Drug Delivery Reviews; 31: 267-285.

3. Vila Jato JL. (1997). Tecnología Farmacéutica Aspectos fundamentales de los sistemas farmacéuticos y operaciones básicas, Editorial Síntesis, pp. 75-90.

4. Rodriguez-Llimos AC, Chappetta D, Szeliga ME, Fernández A, Bregni C. (2003). Micropartículas de alginato conteniendo paracetamol. A.R.S. Farmaceutica, 44(4): 332-342.

5. http://ffyb.uba.ar/farmacotecnia20I/Microencapsulacion.htm

6. Farmacopea de Estados Unidos de America, USP 30-NF25. 